IMF Staff Papers

Vol. 48, No. 3

(C) 2001 International Monetary Fund

\title{
Modeling the IMF's Statistical Discrepancy in the Global Current Account
}

\section{JAIME MARQUEZ and LISA WORKMAN*}

This paper offers a framework for judging when the discrepancy embodied in current account forecasts is large. The first step in implementing this framework involves developing an econometric model explaining the components of the aggregate discrepancy, estimating the associated parameters, and generating the aggregate discrepancy's conditional expectation. The second step is to compare this model-based forecast with the discrepancy embodied in countries' current-account forecasts. If the gap in discrepancies is below a critical value, then the discrepancy embodied in the countries' current account forecasts is not large. Otherwise, the discrepancy is large and calls for a careful reexamination of the associated current account forecasts. [JEL C52, F33]

E or projections of global external imbalances to be useful, they must be internally consistent: external surpluses and deficits across countries must add up

\footnotetext{
*Jaime Marquez is Senior Economist in the Division of International Finance at the Federal Reserve Board, Lisa Workman is a graduate student in economics at Notre Dame University. She was a Research Assistant at the Federal Reserve Board (1999-2001) when work on this paper was undertaken. Extensive comments from David Howard on several versions of this paper and from two anonymous referees are greatly appreciated. Comments from the Editor of IMF Staff Papers and from participants in seminars at the Federal Reserve Board, the spring 2000 meeting of the Midwest International Economics Group (University of Kentucky), and the International Monetary Fund are greatly appreciated. The results of this paper have been replicated by John Green and David Robinson of the IMF's World Economic Outlook Division and we are grateful to them for their time and observations. Comments from Neil Ericsson, Hamid Faruqee, Jon Faust, Gian Maria MilesiFerretti, Andy Levin, Tracy Miller, John Motola, Davidson Omole, Nathan Sheets, Charlie Thomas, John Wilson, and Jonathan Wright are gratefully acknowledged. The views in this paper are solely the responsibility of the authors and should not be interpreted as reflecting the views of the Board of Governors of the Federal Reserve System or of any other person associated with the Federal Reserve System. We use PcGive Professional 9.2 (Hendry and Doornik, 1996) and Portable Troll 1.082 (Hollinger and Spivakovsky, 1996).
} 
to zero. That this adding-up condition does not hold in the data need not, by itself, undermine the usefulness of these projections: reporting mistakes, sampling errors, and recording asymmetries across countries are a fact of life and, when combined, they give rise to a statistical discrepancy. But when this discrepancy reaches the level of the current account surplus of Japan in 1990 ( $\$ 100$ billion), and is projected to reach almost $\$ 300$ billion by 2001 (Figure 1), one cannot avoid questioning the usefulness of such projections.

Sustained discrepancies of this magnitude are worrisome because they undermine the credibility of global current account forecasts. Specifically, if the discrepancy stems from recording practices of a few countries, then their forecasts for growth could be systematically mismeasured with obvious implications for the global consistency of individual country forecasts of the current account. Such consistency is central to studying, for example, which countries will absorb the reduction of the U.S. external deficit.

One tempting response to this statistical discrepancy is to develop a rule to allocate it across countries. Years of work by the IMF suggest, however, that reliance on such rules might further distort the countries' current account forecasts. ${ }^{1}$ Indeed, the evolution of this discrepancy has no obvious statistical pattern and, thus, an allocation rule suitable for one year need not work in other years. Moreover, movements in the statistical discrepancy reflect large and often mutually offsetting movements in its components. This property creates the impression of improved accuracy when just the opposite is true (Figure 2). Thus using a rule to allocate the discrepancy over 1993-97 would reallocate small amountsprecisely the opposite of what is needed.

Facing sustained and large discrepancies in the global current account with no reliable allocation rule leaves practitioners with two courses of action: either ignore the discrepancy and the internal consistency of global forecasts or reexamine the associated current account forecasts if the implied discrepancy is, in some sense, large. In other words, if we denote $C_{i}$ as the current account forecast for the ith country, then $D^{c}=\Sigma_{\forall \mathrm{i}} C_{i}$ is the current account discrepancy associated with those forecasts and the question is whether $D^{c}$ is large enough to merit a revision of the underlying $C_{i}$ s.

Determining whether $D^{c}$ is large involves specifying a reference value and this paper offers a practical approach to determining it. Specifically, as reference value we choose the expected value of the discrepancy. This choice allows us to define a discrepancy as large if it is significantly different from its conditional expectation. Implementing this choice involves developing an econometric model to generate the distribution of the discrepancy and Sections II-IV of this paper document the associated modeling aspects: level of disaggregation, functional form, explanatory variables, and estimation method.

\footnotetext{
${ }^{1}$ The chief study on the global current account discrepancy is the 1987 Report on the World Current Account Discrepancy (IMF, 1987), which focuses on the 1983 discrepancy; its findings have been confirmed in IMF (1996, 1999a, 1999b). The appendix uses a hypothetical example to highlight the potential pitfalls in using fixed rules to allocate the global current account discrepancy across countries.
} 
Figure 1. World Current-Account Discrepancy
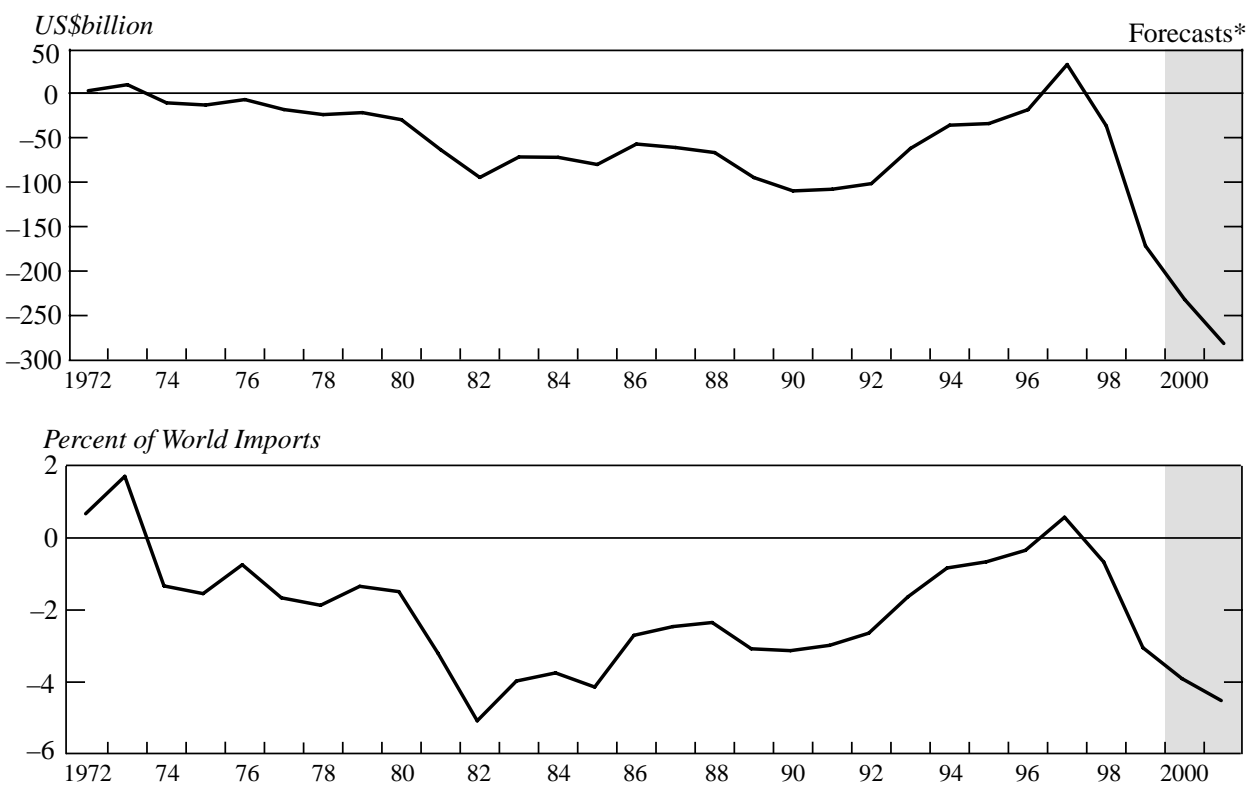

Source: *World Economic Outlook, May 2000.

Figure 2. World Current-Account Discrepancy by Categories (percent of World Imports)

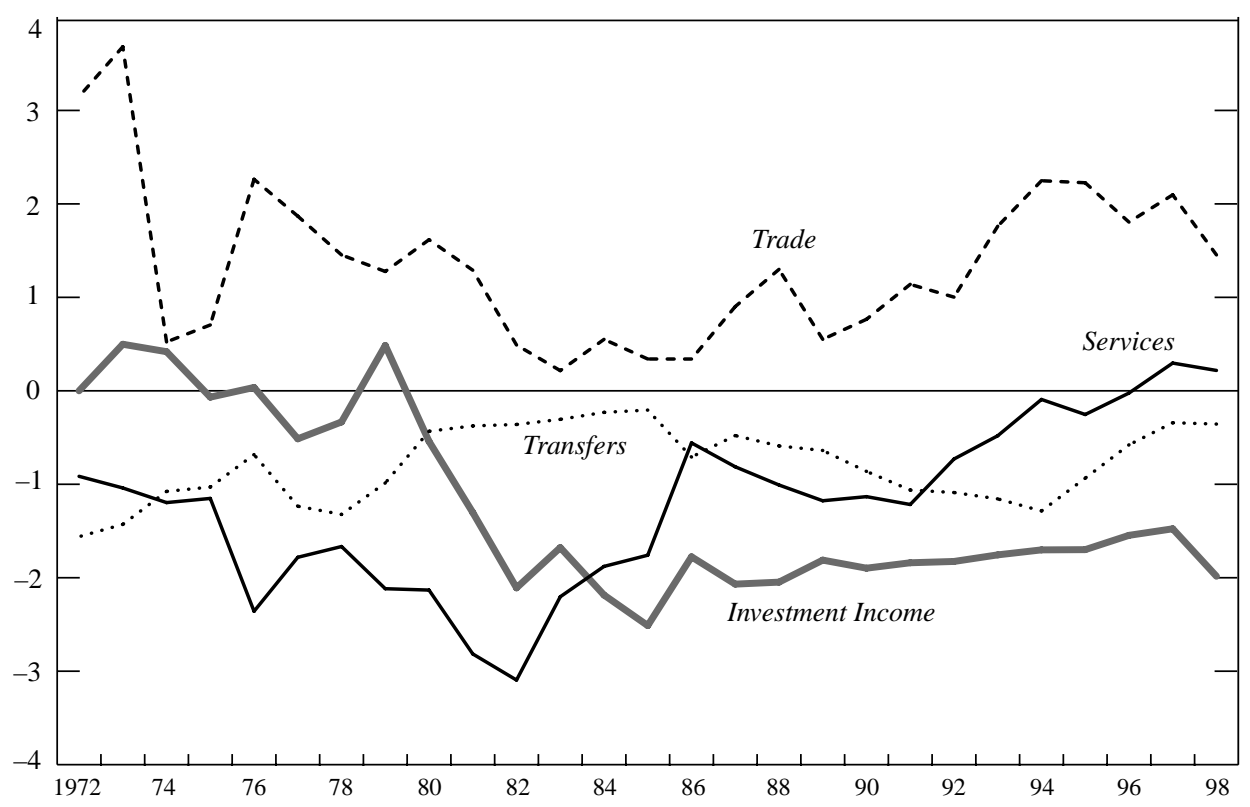


To evaluate the usefulness of the model, Section III asks whether it can detect large discrepancies when large discrepancies are known to occur: not being able to detect a known significant change would question the model's usefulness. As a test case we use the switch in Europe's trade methodology in 1993, which is acknowledged to be responsible for large discrepancies (IMF, 1997, p. 9). We then generate ex ante forecasts of the discrepancy through 2001 and compare them against those reported in the IMF's World Economic Outlook for May 2000. The model identifies the discrepancy in that report as large and calls for a rethinking of the country-based forecasts.

\section{Model Design}

\section{Aggregation}

The model explains the global current account discrepancy, $D$, as the sum of the discrepancies in four global accounts:

$$
D=D_{g}(q)+D_{i}(q)+D_{s}(q)+D_{u}(q)
$$

where $q$ is a vector of explanatory variables, $D_{g}$ is the global discrepancy in the trade account, $D_{i}$ is the global discrepancy in the investment-income account, $D_{s}$ is the global discrepancy in the service account, and $D_{u}$ is the global discrepancy in the unrequited-transfers account.

The alternative to explaining the accounts' discrepancies is to develop a single-equation model for the overall discrepancy, as in Sheets (1998). A single equation is appealing because of its simplicity but it suffers from aggregation pitfalls. Specifically, the global discrepancy might be zero not because of accurate recordings but because discrepancies in various accounts are mutually offsetting (see Figure 2). Coefficient estimates of a single equation would then reflect the happenstance of inaccurate recordings whereas coefficient estimates for separate equations would avoid them.

\section{Analytical Framework}

We differentiate between actual and recorded transactions. Let actual global credits in a given account be $X_{a}$ and actual global debits be $M_{a}$, where $a=g, i, s, u$. Whereas $X_{a} \equiv M_{a}$, the corresponding recorded measures need not be identical:

$$
\begin{aligned}
& X_{a}{ }^{\prime}=X_{a} \cdot\left(1+e_{x a}\right) \\
& M_{a}{ }^{\prime}=M_{a} \cdot\left(1+e_{m a}\right), a=g, i, s, u,
\end{aligned}
$$


where the ' indicates a recorded magnitude, $e_{x a}$ is the error in credits, and $e_{m a}$ is the error in debits. The global discrepancy in that account is:

$$
\begin{aligned}
\mathrm{F}_{a}{ }^{\prime} & =X_{a}{ }^{\prime}-M_{a}{ }^{\prime} \\
& =X_{a}-M_{a}+X_{a} \cdot e_{x a}-M_{a} \cdot e_{m a} \\
& =X_{a} \cdot\left(e_{x a}-e_{m a}\right), a=g, i, s, u .
\end{aligned}
$$

To translate this accounting identity into a statistical model, we postulate that $e_{x a}=e_{x a}\left(q, u_{a}\right)$ and $e_{m a}=e_{m a}\left(q, v_{a}\right)$ where $u_{a}$ and $v_{a}$ are random variables. Thus:

$$
\mathrm{F}_{\mathrm{a}}^{\prime}=X_{a} \cdot\left[e_{x a}\left(q, u_{a}\right)-e_{m a}\left(q, v_{a}\right)\right], a=g, i, s, u .
$$

We now assume that:

$$
X_{a}=\theta_{a} \cdot z_{a}\left(q, w_{a}\right) \cdot M_{w}{ }^{\prime}, a=g, i, s, u,
$$

where $M_{w}{ }^{\prime}$ is recorded world imports and $w_{a}$ is a random variable. With this assumption, we model the importance of a statistical discrepancy as:

$$
\mathrm{F}_{a}{ }^{\prime} / M_{w}{ }^{\prime} \equiv D_{a}=\left[\theta_{a} \cdot z_{a}\left(q, w_{a}\right)\right] \cdot\left[e_{x a}\left(q, u_{a}\right)-e_{m a}\left(q, v_{a}\right)\right], a=g, i, s, u
$$

which is nonlinear in the variables included in $q$.

To illustrate the key features of our approach, assume the simplest formulation:

$$
\begin{aligned}
e_{x a t}-e_{m a t} & =\left(e_{x a}-e_{m a}\right) \cdot\left(\gamma_{a 0}+\gamma_{a 1} \cdot q_{1 t}+u_{a t}\right), u_{a t} \sim N\left(0, \sigma_{a t}^{2}\right) \\
z_{a}\left(q, w_{a}\right) & =\pi_{a 0} \cdot q_{1 t} \text { for } a=g, i, s, u .
\end{aligned}
$$

Then:

$$
\begin{aligned}
D_{a} & =\left(e_{x a}-e_{m a}\right) \cdot\left[\left(\theta_{a} \pi_{a 0}\right) \cdot\left(\gamma_{a 0} \cdot q_{1 t}^{2}+\gamma_{a 1} \cdot q_{1 t}^{2}+u_{a t} \cdot q_{1 t}\right)\right] \\
& =\left(e_{x a}-e_{m a}\right) \cdot\left[1_{a 0} \cdot q_{1 t}+1_{a 1} \cdot q_{1 t}^{2}+1_{a 1} \cdot u_{a t} \cdot q_{1 t}\right], a=g, i, s, u .
\end{aligned}
$$


The term $\left(e_{x a}-e_{m a}\right)$ embodies the factors that give rise to a statistical discrepancy in the first place: reporting mistakes and sampling errors. In the absence of these factors, the actual and the recorded transactions would be equal to each other and there would be no statistical discrepancy. The term in square brackets embodies the factors that account for movements in the (scaled) discrepancy. For example, if $q_{1 t}$ is a variable capturing behavioral incentives to misreport by one of the transactors, then changes in those incentives will induce nonlinear changes in the account's statistical discrepancy. ${ }^{2}$

\section{Statistical Framework}

Our modeling recognizes the roles of simultaneity and dynamics. Simultaneity considerations arise because international transactions are recorded using the principle of double entry. This principle requires recording two accounts simultaneously and, thus, discrepancies in one account could reflect mismeasurements from another. ${ }^{3}$

Dynamic considerations might arise because faulty recording practices are institutionalized and fixing them takes time. One formulation capturing these two features is:

$$
\begin{aligned}
& A_{0} \cdot \Lambda_{t}=A_{1} \cdot \Lambda_{t-1}+B \cdot Q_{t}+U_{t} \\
& D_{t}=1^{\prime} \cdot \Lambda_{t},
\end{aligned}
$$

where $A_{0}$ is a $4 \times 4$ matrix of coefficients recognizing the role of simultaneity; $\Lambda_{t}$ is the $4 \times 1$ vector of discrepancies to be modeled $\left(\Lambda^{\prime}=\left(D_{g}, D_{i}, D_{s}, D_{u}\right) ; A_{1}\right.$ is a $4 \times 4$ matrix of coefficients capturing the importance of dynamic considerations; $B$ is a $4 \times n$ matrix of coefficients; $Q_{t}$ is the vector of explanatory variables consisting of the entries in $q_{t}$ as well as nonlinear terms (more below); $U_{t}$ is the vector of disturbances distributed as $I N\left(0, \Omega_{U t}\right)$; and 1' is a vector of ones.

The reduced form implied by equation (2) is:

$$
\begin{aligned}
& \Lambda_{t}=\Pi_{d} \cdot \Lambda_{t-1}+\Pi_{q} \cdot Q_{t}+V_{t} \\
& D_{t}=1^{\prime} \cdot \Lambda_{t},
\end{aligned}
$$

${ }^{2}$ Our working paper documents how we apply this framework to deriving estimating equations for each account's discrepancy; see http://www.federalreserve.gov/pubs/ifdp/2000/678/ifdp678.pdf.

${ }^{3}$ For example, a donor country may record the value of a transfer as both a credit (such as merchandise exports for aid) and as a debit (unrequited transfer). The recipient country might debit the trade account (e.g., merchandise imports) and credit the capital account (e.g., capital inflow) instead of crediting unrequited transfers. 
where $\Pi_{d}=A_{0}^{-1} \cdot A_{1}, \Pi_{q}=A_{0}^{-1} \cdot B$, and $V_{t}=A_{0}^{-1} \cdot U_{t} \sim N\left(0, \Omega_{V t}\right)$. Section III uses the Full Information Maximum Likelihood method (FIML) for parameter estimation and the implements dynamic simulations to estimate the expected global discrepancy at time $t$ as:

$$
\hat{E}\left(D_{t}\right)=1^{\prime} \cdot E\left(\hat{\Pi}_{d} \cdot \hat{\Lambda}_{t-1}+\hat{\Pi}_{q} \cdot Q_{t}+V_{t}\right),
$$

where a circumflex denotes an estimated magnitude. Note that $\hat{E}\left(D_{t}\right)$ is conditioning on the model's own generated values for the lagged endogenous variables and not on historical values. The estimate of the variance of the discrepancy at time $t$ is:

$$
\operatorname{vâr}\left(D_{t}\right)=1^{\prime} \cdot \operatorname{var}\left(\hat{\Pi}_{d} \cdot \hat{\Lambda}_{t-1}+\hat{\Pi}_{q} \cdot Q_{t}+V_{t}\right)
$$

Note that $\operatorname{var}\left(D_{t}\right)$ varies with changes in the explanatory variables. Furthermore, reliance on FIML allows for the correlations across the residuals of the model to affect $\operatorname{var}\left(D_{t}\right)$.

One can use these equations to test whether the discrepancy embodied in countries' current account forecasts, $D_{t}^{c}$, is large. Specifically, the null and alternative hypotheses are:

$$
H_{0}: E\left(D_{t}\right)=D_{t}^{c}
$$

and

$$
H_{1}: E\left(D_{t}\right) \neq D_{t}^{c},
$$

and the test statistic is:

$$
\tau=\frac{D_{t}^{c}-\hat{E}\left(D_{t}\right)}{\sqrt{\operatorname{var}}\left(D_{t}\right)} .
$$

If $V_{t} \sim N\left(0, \Omega_{V}\right)$, then finding that $|\tau|>2$ means that $D_{t}^{c}$ is statistically different from its expected value at the 5 percent significance level. We interpret such a finding as suggesting that $D_{t}^{c}$ is large. 


\section{Model Assembly}

\section{Selection of Explanatory Variables}

Looking to economic theory for what variables to include in $q$ is not fruitful here because there is no economic theory of current account discrepancies as such. Thus to select the explanatory variables, we identify the forces responsible for each account's discrepancy and then translate those forces into a list of macroeconomic variables. ${ }^{4}$ This approach yields too many variables to consider and thus, to discriminate among them, we invoke additional criteria. First, the data must be available on a timely basis. Arguing that a variable should be included in a model because its coefficient is highly significant loses its force if the associated data are available with a long delay. Second, given the annual frequency of observations, the number of explanatory variables should be as small as possible. Third, generating a forecast of $q$ should not be more difficult than generating forecasts of the discrepancies directly. Finally, the estimation results cannot violate the maintained assumptions for the residuals. These assumptions are central to the definition of a large discrepancy.

\section{Discrepancies in trade}

The factors responsible for a discrepancy in the global trade account are transportation delays, asymmetric valuations, and quality differentials in recording practices. Transportation delays in shipping merchandise imply that recorded increases in export credits are not accompanied by simultaneous recorded increases in import debits. To translate the role of these shipment delays into an explanatory variable, we assume that fluctuations in world trade are driven by fluctuations in economic activity. Thus faster world growth raises recorded exports ahead of recorded imports and raises net credits in the global trade balance.

Asymmetric valuations arise whenever different prices are used to value the same transaction. For example, recipients of oil subsidies from the Organization of the Petroleum Exporting Countries (OPEC) could record oil imports (debits) at the subsidized price whereas OPEC could record the corresponding oil exports (credits) at the market price. In that case, debits would increase less than credits thus inducing a discrepancy in the global trade account. Another example involves the use of different exchange rates to value the same transaction by at least one of the reporting countries. To model these valuation asymmetries we use the price of oil as a proxy for commodity prices, and the U.S. federal funds rate as a proxy for

\footnotetext{
${ }^{4}$ Idiosyncratic recording practices can also induce discrepancies. For example, Bermuda, the Cayman Islands, and Hong Kong SAR combine direct-investment income with other income measures. Similarly, Middle Eastern oil exporters do not report cross-border investment income of private nonbanks (IMF, 1987, pp. 57-58). By their nature, idiosyncratic factors lack an obvious representation in terms of a macroeconomic variable.
} 
exchange rates. The alternative of including in $q$ the numerous exchange rates would exhaust the degrees of freedom.

Differentials in recording quality across countries might help explain movements in the discrepancies. Specifically, if countries with high-quality data increase their share of world trade, then one would expect a reduction in the existing trade discrepancy. To model this possibility, we assume that the United States is the high-quality data country and postulate that if the U.S. share of world imports increases, then there would be a reduction of net credits in the trade discrepancy, all else given. A more concrete example of the role of quality involves the change in methodologies for collecting intra-European Union (EU) trade data by the EU in 1993: a switch from custom records to value-added tax records (IMF, 1997, p. 9). The IMF estimates that this switch induced an excess of credits over debits of $\$ 40$ billion a year (IMF, 1999a, p. 4). We model this effect with a dummy variable. ${ }^{5}$

\section{Discrepancies in investment income}

Discrepancies in this account reflect misrecordings in portfolio-investment income and direct-investment income. These discrepancies stem from incentives to understate capital outflows, the growth of offshore financial centers, and recording idiosyncrasies. ${ }^{6}$ The incentive to underreport capital outflows arises from tax avoidance on the corresponding income. This tax-evasion incentive leads to an underreporting of investment income because accounting practices use cumulated capital outflows to estimate the corresponding stock of claims on foreigners, which is then used to compute investment income. Thus understating capital outflows translates into understating the associated income. To model this factor, we assume that an increase in the U.S. federal funds rate accentuates the incentive to understate capital outflows, which results in an underestimate of the stock of claims on foreigners and the resulting investment income.

The growth of offshore financial centers is contributing to the discrepancy in investment income by undermining the ability of statistical agencies to track financial transactions. Specifically, such centers are largely unrelated to domestic activities of the host country and typically do not have to report to the host's statistical agencies. ${ }^{7}$ Also, the associated transactions involve securitization with numerous

\footnotetext{
${ }^{5}$ To investigate this possibility further, we use the IMF's Direction of Trade that reports bilateral trade data. We then compute intra-EU credits and debits and find a sharp increase in net credits starting in 1993. As a fraction of EU imports from their members, the discrepancy increases from about 1 percent prior to 1993 to 7.3 percent in 1993. This gap reaches a maximum of 9.3 percent in 1996 .

${ }^{6}$ Portfolio income includes interest payments/receipts among banks, interest and dividends on securities, commercial paper, mortgages, and supplier credits. Direct-investment income includes earnings of foreign subsidiaries, earnings of unincorporated business in foreign countries, and interest of foreignincorporated affiliates and branches. The bulk of these discrepancies stems from discrepancies in portfolio-investment income.

${ }^{7}$ The new offshore financial centers are located in Hong Kong SAR, Singapore, Bahrain, the Bahamas, Cayman Islands, and Panama; Bahrain's operations are recorded in that country's statistics. These centers offer unregulated operations and tax advantages not offered by traditional centers (e.g., New York, London, and Zurich).
} 
participants, not all of whom report to any national compilers. ${ }^{8}$ Expecting financial innovation to grow over time, we use a trend to capture the effect of this process on the discrepancy.

Recording idiosyncrasies come in two flavors: misclassifications and asymmetries. Misclassifications arise from the ambiguity of the term lasting interest, which is the criterion used for classifying foreign direct investment. This ambiguity has led some countries to record reinvested earnings as a capital inflow from the parent company (IMF, 1987, p. 36) and not as investment income. ${ }^{9}$

Asymmetries arise from cross-country differences in recording practices for a given transaction. (See footnote 3.) Given that both misclassifications and asymmetries reflect institutional practices, we model the persistence of errors they induce by including the lag of the discrepancy of the investment income account as an explanatory variable.

\section{Discrepancy in services}

The discrepancy in services arises from misrecordings in travel expenses, shipping, and other transportation services. This discrepancy is declining but that trend conceals the growing importance of errors in shipping (Table 1). ${ }^{10}$

Given that most countries have good records of their payments to foreign shippers, the discrepancy arises from underreporting of revenue by ship operators. Indeed, ship operators of the world's largest fleets claim Greece, Hong Kong SAR, and countries in Eastern Europe as residence, but these economies do not report such earnings to the IMF (IMF, 1996, p. 146). ${ }^{11}$

To model this discrepancy we assume (i) that shippers seek to avoid income taxes and thus underreport their shipping revenues and (ii) that their propensity to underreport is directly related to the price of oil. We use this price because oil is an important commodity in maritime transportation and because the price of oil is correlated with the prices of other raw materials. ${ }^{12}$

Counteracting the effects of underreporting credits is the adoption of alternative modes of transportation. Specifically, declines in the physical weight of products allow their transportation using the growing air fleet. The associated tight security procedures virtually guarantee that all the items transported are accounted

\footnotetext{
${ }^{8}$ Securitization takes place when direct loans by banks are replaced by underwriting commitments that do not appear on banks' balance sheets.

${ }^{9}$ The IMF's approach to measuring reinvested earnings requires direct questioning of multinational enterprises, which is difficult given the resources available. Because of these difficulties, the IMF recommends dropping this account from the global sum of investment-income accounts (IMF, 1987, p. 43).

${ }^{10}$ Shipment debits include the cost of freight, insurance, and those distribution services paid by the importer; shipment credits include gross revenue on freight earned by vessels operated by residents of the reporting country regardless of the flag registry of the vessel.

${ }^{11}$ Moreover, the Greek balance of payments excludes the operations of the Greek fleet because the owners of that fleet do not reside in Greece and, as far as the IMF is aware, they are not residents in other countries either (IMF, 1987, p. 90).

${ }^{12} \mathrm{We}$ also considered the IMF's Commodity Price Index, but we did not find it to exert a significant influence on the behavior of discrepancies.
} 
MODEUNG THE IMF'S STATISTICAL DISCREPANCY

\begin{tabular}{|c|c|c|c|c|c|c|c|c|}
\hline \multicolumn{9}{|c|}{$\begin{array}{l}\text { Table 1. Discrepancies in Services Account } \\
\text { (in billions of U.S. dollars) }\end{array}$} \\
\hline & 1991 & 1992 & 1993 & 1994 & 1995 & 1996 & 1997 & 1998 \\
\hline Services & -44.1 & -28.1 & -18.3 & -4.0 & -13.1 & -1.3 & 16.6 & 12.0 \\
\hline Shipping & -50.6 & -53.0 & -55.8 & -55.7 & -66.3 & -63.6 & -64.8 & -60.9 \\
\hline
\end{tabular}

for, leaving little room for misreporting. To the extent that the decline in physical weight of products will continue, we use a time trend to capture how substitution away from maritime shipping reduces the scope for underreporting export services.

\section{Discrepancies in unrequited transfers}

Discrepancies in transfers arise from two sources: the recording asymmetries of workers' remittances and the exclusion of the intermediation by international donor organizations from balance of payments accounts. Asymmetries in recording remittances arise when (i) the host country treats temporary workers as residents, recording their remittances as unrequited transfers; and (ii) the country of origin also treats these workers as residents, recording their remittances not as unrequited transfers but as service exports (IMF, 1987, p. 104).

Intermediation by international donor agencies are excluded from countries' balance of payments because these agencies are not considered residents of any country; some of these agencies report to the IMF. As long as this intermediation operates without delays, the transaction by itself does not generate a statistical discrepancy. Over a given horizon, however, these institutions receive contributions for assistance in excess of their disbursements. The shortfall in disbursements is not recorded because these international institutions do not conform to the principle of residency (IMF, 1987, p. 103), giving rise to the account's discrepancy.

A convenient way of modeling this feature is to recognize that if the share of intermediation by international institutions declines, then so will the discrepancy it induces. The share of intermediation declines when donor countries provide their assistance directly to recipient countries and avoid the side effects of the intermediary role of international institutions (delays and residency). To this end we assume that OPEC members, who have been important donors in the past, are more likely to be donor countries the higher the price of oil. An increase in that price would, if we are correct, translate into greater assistance from OPEC, a reduction in the intermediation from international institutions, and a decline in the excess of debits over credits in transfers. 


\section{Summary}

Table 2 lists the factors we have identified to explain movements in the various discrepancies. This list is what we denoted as $q$ :

$$
q^{\prime}=\left(\begin{array}{llllll}
d Y / Y & P_{o} & R & M_{u s} & d u m & \text { trend }
\end{array}\right)
$$

where $d Y / Y$ is world growth, $P_{o}$ is the nominal price of oil, $R$ is the nominal U.S. federal funds rate, $M_{u s}$ is the U.S. share in world imports, and dum is a dummy for European trade. To recognize the role of nonlinearities, we expand this list to include the squares of the price of oil and the interest rate as well as the interactions between these two variables and the trend. The resulting list of explanatory variables is denoted as $Q$ :

$$
Q^{\prime}=\left(\text { Intercept } \quad q^{\prime} \quad P_{o}^{2} \quad R^{2} \quad P_{o} \cdot \text { trend } R \cdot \text { trend }\right) \text {. }
$$

We want to emphasize that Table 2 does not offer a list of zero restrictions on the coefficients of the reduced form. The simultaneous character of the model allows all exogenous variables to affect the discrepancies in all of the accounts and our statistical analysis allows for that possibility.

\section{Parameter Estimation}

Based on annual data from 1972 to 1998 , Table 3 shows the least-squares estimates for the unrestricted reduced form, equation (4). The results reveal numerous $t$-ratios below the 5 percent critical value, which is not surprising given the relatively small number of degrees of freedom. Second, the maintained assumptions for the residuals are supported empirically. ${ }^{13}$

Using a log-likelihood ratio test, we eliminate variables that are not jointly significant and reestimate the parameters of the restricted reduced form using FIML. According to the estimates, the data support the maintained assumptions for the residuals (Table 4) but persistence effects are small and limited to discrepancies in transfers.

Also, the dummy for the switch in European data methods is positive and significant, and suggests that the switch of recording practices of Europe raised the trade discrepancy by about 0.9 percentage points of world imports. The coefficient

\footnotetext{
${ }^{13}$ We test for joint normality using the Jarque-Bera test; the statistic is distributed as $\chi^{2}(n \cdot 2)$ where $n$ is the number of equations. We test for joint serial independence with an F-test for the hypothesis that the coefficients for a VAR(1) of the estimation residuals are jointly equal to zero. We applied an ARCH test to each equation separately and the results cannot reject (not shown) the hypothesis of homoskedasticity. See Hendry and Doornik (1996) for details.
} 
MODEUNG THE IMF'S STATISTICAL DISCREPANCY

Table 2. Factors Explaining the Global Discrepancies

$\begin{array}{lll}\begin{array}{l}\text { Variables: } q \\ \text { World growth: } d Y / Y\end{array} & \text { Factor Modeled } & \text { Account } \\ \text { Recording delays } & \text { Trade } \\ \text { Oil prices: } P_{o} & \begin{array}{l}\text { Valuation asymmetries } \\ \text { Tax evasion } \\ \text { Disbursement delays }\end{array} & \begin{array}{l}\text { Trade } \\ \text { Services } \\ \text { Transfers }\end{array} \\ & \begin{array}{l}\text { Tax evasion } \\ \text { Valuation asymmetries }\end{array} & \begin{array}{l}\text { Investment income } \\ \text { Trade }\end{array} \\ \text { U.S. interest rate: } R & \text { Quality differentials in data } & \text { Trade } \\ \text { U.S. share of world } & \text { Financial globalization } & \begin{array}{l}\text { Investment income } \\ \text { imports: } M_{u s}\end{array} \\ \text { Trend } & \text { Transportation technology } & \text { Services } \\ & \text { Methodological changes } & \text { Trade }\end{array}$

for the trend is positive and significant for services: the underreporting of credits due to maritime shipping is ameliorated by the growing role played by the alternatives to maritime shipping.

Nonlinearities (interactions and squared terms) have statistically significant coefficients, which call for model simulations to evaluate the effects of changes in the remaining variables; we use one-year shocks evaluated in 1998. Based on these simulations, a 10 percent increase in the price of oil lowers net credits in the global discrepancy by 0.03 percent of world imports (Table 5). This small effect reflects offsetting responses from the various accounts. An increase of the federal funds rate by 1 percentage point lowers net credits in the discrepancies for investment income and services; net credits in the overall discrepancy decline by 0.24 percent of world imports or about $\$ 13$ billion. Raising the world's growth rate by 1 percentage point increases net credits in the trade discrepancy: faster growth accelerates trade and accentuates the extent to which trade credits are recorded ahead of trade debits. The overall discrepancy experiences an increase in net credits of 0.64 percentage points of world imports or about $\$ 35$ billion.

An increase of the U.S. share of world imports by 1 percentage point reduces net credits in the trade discrepancy by 0.25 percent of world imports ( $\$ 14$ billion) given that a greater fraction of world trade is being recorded by the country with the high-quality data. Higher U.S. imports also affect the investment income discrepancy given that financing an increase of U.S. imports involves an increase in foreign capital outflows. The underreporting of these outflows accentuates the understating of claims of the rest of the world on the United States and the associated interest receipts. Finally, to the extent that a fraction of the increase in U.S. imports is transported by the U.S. fleet, shipping credits that would not have been 
Jaime Marquez and Lisa Workman

Table 3. Estimates of Unrestricted Reduced Form-OLS: 1972-98

\begin{tabular}{|c|c|c|c|c|}
\hline & Trade $D_{g t}$ & Services $D_{s t}$ & Investment $D_{i t}$ & Transfers $D_{u t}$ \\
\hline$D_{g, t-1}$ & 0.15 & -0.26 & -0.19 & 0.04 \\
\hline$D_{s, t-1}$ & 0.02 & -0.06 & 0.08 & $0.46^{*}$ \\
\hline$D_{i, t-1}$ & -0.12 & 0.54 & 0.24 & -0.12 \\
\hline$D_{u, t-1}$ & -0.29 & -0.24 & 0.31 & $1.05^{*}$ \\
\hline$d Y / Y$ & $0.37 *$ & -0.03 & $0.26^{*}$ & 0.01 \\
\hline$P_{o}$ & $-0.24^{*}$ & -0.11 & 0.15 & 0.03 \\
\hline$R$ & -0.49 & 0.50 & 0.57 & 0.09 \\
\hline$M_{u s}$ & -0.19 & 0.17 & $-0.34 *$ & -0.04 \\
\hline Trend & -0.07 & 0.18 & 0.12 & -0.04 \\
\hline dum & 0.63 & 0.06 & 0.58 & 0.17 \\
\hline$P_{o}^{2}$ & $0.01 *$ & 0.00 & -0.004 & 0.003 \\
\hline$R^{2}$ & $0.02 *$ & -0.01 & -0.012 & -0.01 \\
\hline$P_{o} \cdot$ trend & 0.00 & 0.003 & -0.003 & 0.00 \\
\hline$R \cdot$ trend & 0.01 & -0.02 & -0.02 & -0.002 \\
\hline Intercept & $6.67 *$ & $-5.70 *$ & 0.14 & 0.71 \\
\hline SER & 0.297 & 0.354 & 0.337 & 0.181 \\
\hline \multicolumn{5}{|c|}{$\begin{array}{l}* t \text {-ratio above the } 5 \text { percent level. } P_{o}=\text { oil price; } R=\text { federal funds rate; } d Y / Y=\text { world growth } \\
d u m=\text { dummy for European trade; and } M_{u s}=\text { U.S. share in world imports. }\end{array}$} \\
\hline \multicolumn{5}{|c|}{ Hypothesis Testing } \\
\hline \multicolumn{2}{|c|}{ Null Hypothesis } & \multicolumn{2}{|c|}{ Test Statistic } & Result ( $p$-level) \\
\hline \multicolumn{2}{|c|}{ Residuals are jointly normal } & \multicolumn{2}{|c|}{$\chi^{2}(8)$} & $11.845(0.16)$ \\
\hline \multicolumn{3}{|c|}{ Residuals are jointly serially independent } & \multicolumn{2}{|c|}{$1.54(0.23)$} \\
\hline
\end{tabular}

recorded are now being reported with an increase in net credits of the service discrepancy. Figure 3 compares historical values against model predictions. ${ }^{14}$

Judging by the mean absolute errors (MAE), either as a percentage of world imports and in U.S. dollars, the predictions of the model are close to historical values and the residuals are not one-sided. The exception is the transfer equation, which shows systematic deviations during the 1990s.

\section{Model Applications}

For the model developed here to be useful, it should detect large discrepancies when large discrepancies are known to occur. According to the IMF

${ }^{14}$ The predicted value is $\hat{\Lambda}_{t}=\hat{\prod}_{d} \cdot \hat{\Lambda}_{t-1}+\hat{\prod}_{q} \cdot Q_{t}$ and thus we use the model's own predictions for the lagged endogenous variables instead of the historical values. We also examined one-step, out of sample, predictions over 1996-98; the results are comparable to those reported here. 
MODEUNG THE IMF'S STATISTICAL DISCREPANCY

Table 4. Estimates of Restricted Reduced Form—FIML: 1972-981

\begin{tabular}{|c|c|c|c|c|c|c|c|c|}
\hline & \multicolumn{2}{|c|}{ Trade $D_{g t}$} & \multicolumn{2}{|c|}{ Services $D_{s t}$} & \multicolumn{2}{|c|}{ Investment $D_{i t}$} & \multicolumn{2}{|c|}{ Transfers $D_{u t}$} \\
\hline$D_{g, t-1}$ & - & & - & & - & & - & \\
\hline$D_{s, t-1}$ & - & & - & & - & & 0.35 & $(0.08)$ \\
\hline$D_{i, t-1}$ & - & & 0.25 & $(0.11)$ & - & & - & \\
\hline$D_{u, t-1}$ & - & & - & & - & & 0.84 & $(0.1)$ \\
\hline$d Y / Y$ & 0.40 & $(0.03)$ & - & & 0.23 & $(0.06)$ & - & \\
\hline$P_{o}$ & -0.20 & $(0.03)$ & -0.11 & $(0.02)$ & 0.11 & $(0.04)$ & - & \\
\hline$R$ & -0.07 & $(0.03)$ & 0.14 & $(0.06)$ & 0.23 & $(0.03)$ & - & \\
\hline$M_{u s}$ & -0.25 & $(0.04)$ & 0.13 & $(0.06)$ & -0.30 & $(0.06)$ & - & \\
\hline Trend & - & & 0.09 & $(0.03)$ & - & & -0.02 & $(0.01)$ \\
\hline dum & 0.86 & $(0.03)$ & - & & 0.58 & $(0.18)$ & - & \\
\hline $\begin{array}{l}P_{o}^{2} \\
(0.0001)\end{array}$ & 0.005 & $(0.0006)$ & - & & -0.003 & $(0.001)$ & 0.0007 & \\
\hline$R^{2}$ & - & & - & & - & & - & \\
\hline$P_{o} \cdot$ trend & - & & 0.005 & $(0.001)$ & - & & - & \\
\hline$R \cdot$ trend & 0.004 & $(0.001)$ & -0.01 & $(0.004)$ & -0.01 & $(0.002)$ & - & \\
\hline Intercept & 5.56 & $(0.62)$ & -3.4 & (1.15) & 1.11 & $(0.70)$ & 0.34 & $(0.25)$ \\
\hline SER & 0.281 & & 0.339 & & 0.329 & & 0.173 & \\
\hline
\end{tabular}

${ }^{1}$ Entries in parentheses are heteroskedasticity-corrected standard errors. $P_{o}=$ oil price; $R=$ federal funds rate; $d Y / Y=$ world growth; $d u m=$ dummy for European trade; and $M_{u s}=$ U.S. share in world imports.

Hypothesis Testing

Null Hypothesis

Residuals are jointly normal

Residuals are jointly serially independent

Overidentifying restrictions hold

\section{Test Statistic}

$\chi^{2}(8)$
$F(16,37)$
$\chi^{2}(31)$

Result ( $p$-level)

$3.57(0.89)$
$0.84(0.64)$
$34.57(0.30)$

(IMF, 1997, p. 9), the change in European methodology for collecting trade data induced a major increase in the trade discrepancy, and the question is whether the model detects it as such. Thus, the null and alternative hypotheses are:

$$
H_{0}: E\left(D_{t}\right)=D_{t}^{c}
$$

and 
Jaime Marquez and Lisa Workman

Table 5. Responses to Exogenous Shocks ${ }^{1}$

\begin{tabular}{lrrrr} 
Shock $\rightarrow$ & \multicolumn{1}{c}{$\Delta P_{o}$} & \multicolumn{1}{c}{$\Delta$} & $\Delta d Y / Y$ & $\Delta M_{u s}$ \\
$\downarrow$ Response & & & & \\
$\Delta D_{g t}$ & -0.10 & 0.03 & 0.40 & -0.25 \\
$\Delta D_{i t}$ & 0.03 & -0.12 & 0.23 & -0.30 \\
$\Delta D_{s t}$ & 0.02 & -0.15 & 0.00 & 0.13 \\
$\Delta D_{u t}$ & 0.02 & 0.00 & 0.00 & 0.00 \\
$\Delta D$ & -0.03 & -0.24 & 0.64 & -0.42
\end{tabular}

${ }^{1}$ Fraction of world imports in 1998 (\$5,543 billion; IMF, International Financial Statistics, September 1999).

$$
H_{1}: E\left(D_{t}\right) \neq D_{t}^{c},
$$

where $D_{t}^{c}$ is the observed value for the discrepancy at date $t, t=1993-98$. A rejection of the null hypothesis means that the model identifies as large the change in European methods to collect data.

Being able to identify statistically large discrepancies is a necessary but not a sufficient condition to judge the model's usefulness. Specifically, this switch is credited with an increase in net credits of the trade discrepancy. Thus, model predictions that do not use post-1992 data for parameter estimation should understate net credits in the trade discrepancy. Also, the recorded increase in the trade discrepancy tended to offset the discrepancy in investment income (see Figure 2) and induced a seemingly small recorded global discrepancy. Thus, model predictions that exclude the switch should show a worsening of the global discrepancy. Finally, we need evidence of stability in the model's parameters to avoid confusing the effects of parameter instability with the effects of changes in data collection methods.

To implement the test, we start by estimating the model's parameters with data through 1992, which excludes post-switch observations. Comparing the estimation results with those based on the full sample reveals that both sets of parameter estimates are virtually identical (Table 6). With one exception, neither sign nor statistical significance of the estimates change, as a result of using the shorter sample. ${ }^{15}$ Also, the maintained assumptions for the residuals are supported empirically. Moreover, relative to the parameters of the unrestricted reduced form estimated with data through 1992, the log-likelihood ratio test does not reject the same set of zero restrictions. Overall, this evidence rules out parameter instability as a factor in a finding of large discrepancies. ${ }^{16}$

\footnotetext{
${ }^{15}$ The exception is the coefficient for interaction of trend and oil prices in the service equation: significant with the full sample and insignificant otherwise.

${ }^{16} \mathrm{We}$ examined the sensitivity of the estimated parameters (unconstrained and restricted reduced forms) to using the London interbank offered rate (LIBOR) on six-month instruments instead of the U.S. federal funds rate. We find that the point estimates are quite robust but the zero restrictions for the shorter sample are rejected for the model based on the LIBOR. Thus one cannot determine whether ex post tests from the LIBOR-based model are due to parameter instability.
} 
Figure 3. Actual and Simulated Values-Constrained Reduced Form
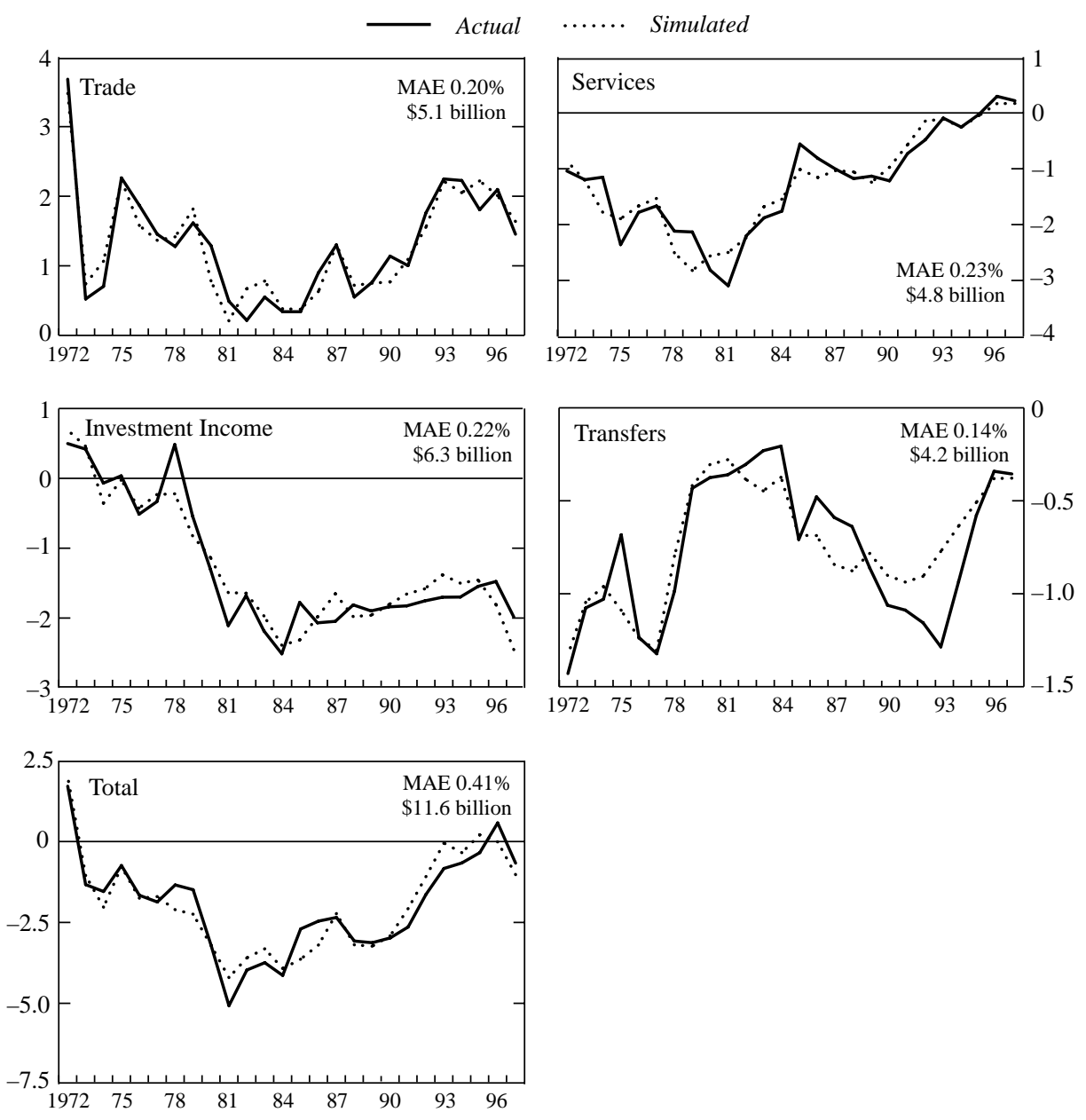

Given the coefficient estimates, we use dynamic simulations to generate predictions for 1993-98, with 1992 as the initial condition:

$$
\hat{\Lambda}_{t}=\hat{\Pi}_{s d} \cdot \hat{\Lambda}_{t-1}+\hat{\Pi}_{s q} \cdot Q_{t}
$$

and

$$
\hat{E}\left(D_{t}\right)=1^{\prime} \cdot \hat{\Lambda}_{t} \quad \text { for } t=1993-98
$$

where the subscript $s$ denotes that the estimates use the short sample (1972-92). If 
Jaime Marquez and Lisa Workman

Table 6. Parameter Estimates with FIML, 1972-98 and 1972-92

\begin{tabular}{lccccccccc} 
& \multicolumn{2}{c}{ Trade $D_{g t}$} & \multicolumn{2}{c}{ Services $D_{s t}$} & \multicolumn{2}{c}{ Investment $D_{i t}$} & \multicolumn{2}{c}{ Transfers $D_{u t}$} \\
& $72-98$ & $72-92$ & $72-98$ & $72-92$ & $72-98$ & $72-92$ & $72-98$ & $72-92$ \\
$D_{g, t-1}$ & - & - & - & - & - & - & - & - \\
$D_{s, t-1}$ & - & - & - & - & - & - & 0.35 & 0.35 \\
$D_{i, t-1}$ & - & - & $0.25^{*}$ & $0.33^{*}$ & - & - & - & - \\
$D_{u, t-1}$ & - & - & - & - & - & - & $0.84^{*}$ & $0.84^{*}$ \\
& & & & & & & & \\
$R \cdot$ trend & $0.004^{*}$ & $0.004^{*}$ & $-0.01^{*}$ & $-0.01^{*}$ & $-0.01^{*}$ & $-0.01^{*}$ & - & - \\
Trend & - & - & $0.09^{*}$ & $0.17^{*}$ & - & - & $-0.02^{*}$ & $-0.02^{*}$ \\
$P_{o}$ & $-0.20^{*}$ & $-0.25^{*}$ & $-0.11^{*}$ & $-0.07^{*}$ & $0.11^{*}$ & $0.20^{*}$ & - & - \\
$P_{o}^{2}$ & $0.005^{*}$ & $0.01^{*}$ & - & - & $-0.003^{*}$ & $-0.005^{*}$ & $0.0007^{*}$ & $0.0007^{*}$ \\
& & & & & & & & & \\
$R$ & $-0.07^{*}$ & $-0.10^{*}$ & $0.14^{*}$ & $0.16^{*}$ & $0.23^{*}$ & $0.25^{*}$ & - & - \\
$d Y / Y$ & $0.40^{*}$ & $0.36^{*}$ & - & - & $0.23^{*}$ & $0.30^{*}$ & - & - \\
$P_{o} \cdot$ trend & - & - & $0.005^{*}$ & 0.001 & - & - & - & - \\
$M_{u s}$ & $-0.25^{*}$ & $-0.21^{*}$ & $0.13^{*}$ & $0.16^{*}$ & $-0.30^{*}$ & $-0.32^{*}$ & - & - \\
Intercept & $5.56^{*}$ & $5.83^{*}$ & $-3.4^{*}$ & $-4.44^{*}$ & 1.11 & 0.45 & 0.34 & 0.36 \\
SER & & & & & & & & \\
& 0.281 & 0.294 & 0.339 & 0.356 & 0.329 & 0.331 & 0.173 & 0.183
\end{tabular}

${ }^{*}$ Statistical significance at the 5 percent level.

Hypothesis Testing with Observations Ending in 1992

$\begin{array}{lll}\text { Null Hypothesis } & \text { Test Statistic } & \text { Result }(p \text {-level) } \\ \text { Vector of residuals is normal } & \chi^{2}(8) & 8.19(0.41) \\ \text { Vector of residuals is serially independent } & F(16,22) & 1.77(0.11) \\ \text { Overidentifying restrictions hold } & \chi^{2}(29) & 41.14(0.07)\end{array}$

$$
\left|D_{t}^{c}-\hat{E}\left(D_{t}\right)\right|>\hat{\delta}_{t}=2 \cdot \sqrt{\operatorname{var}\left(D_{t}\right)},
$$

then the observed discrepancy differs significantly from its expected value and we interpret this result as a large discrepancy.

Figure 4 reports the results, which reveal statistically significant underpredictions in the trade discrepancy and overprediction for the overall discrepancy, just as one expects. Overall, the results show that the model's confidence intervals are narrow enough to detect the European switch in data recording procedures as a major development. By itself, this finding does not constitute an endorsement of the approach. However, not being able to identify a known significant change would question its usefulness. 
Figure 4. 95 percent Confidence Bands for Forecast Discrepancies, 1993-98 (percent of World Imports)
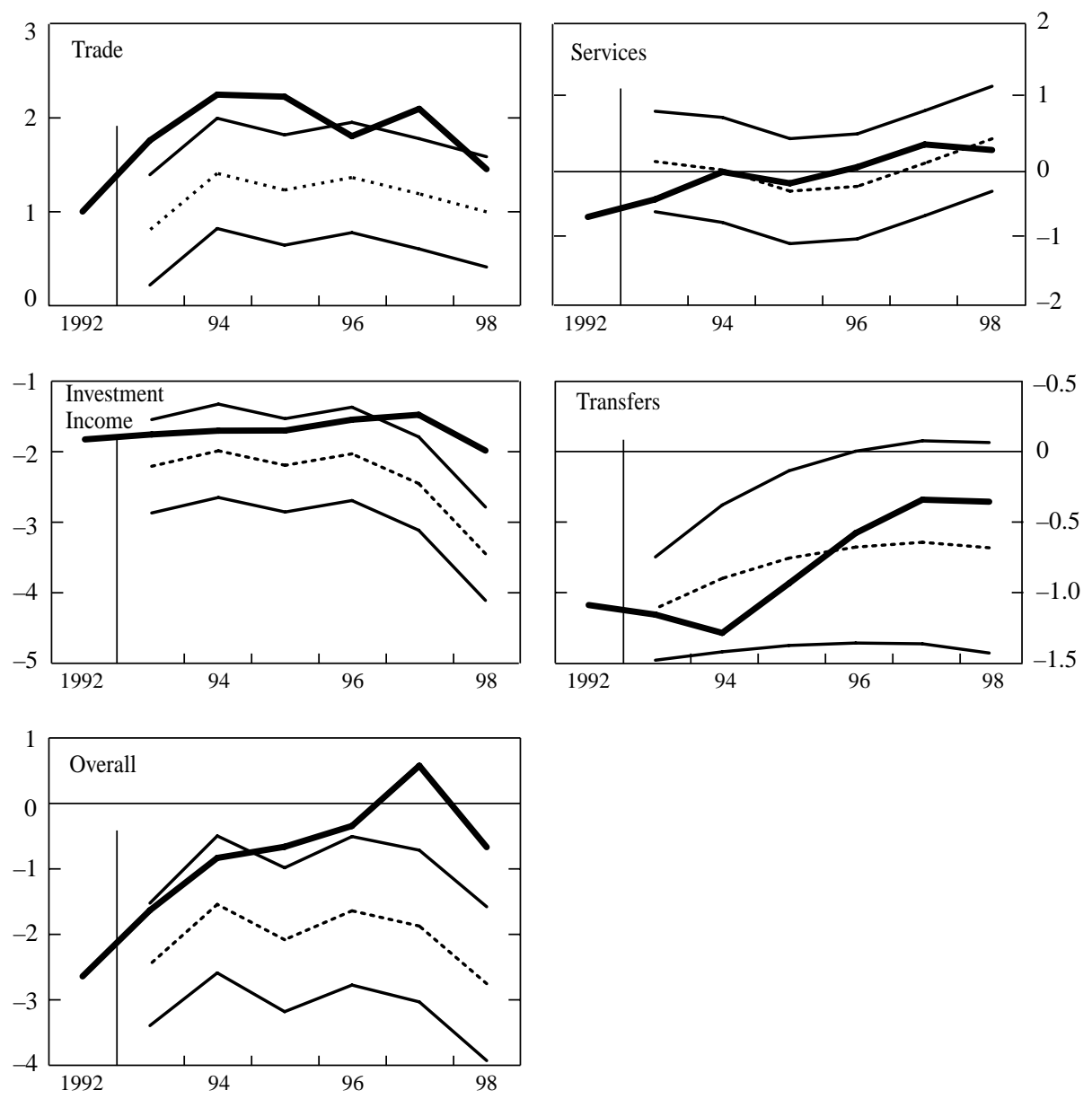

We now test whether the IMF's figures for the overall discrepancy over 1999-2001 are large. To this end we use the IMF's extrapolations for the exogenous variables (Table 7). ${ }^{17}$ The results suggest that the IMF's current account predictions embody a global discrepancy $D_{t}^{c}$ that is significantly different from our model's expectation of that discrepancy, $\hat{E}\left(D_{t}\right)$ (Figure 5). This finding calls, according to our approach, for a rethinking of the current account forecasts for the individual countries.

${ }^{17}$ We apply the growth rates for oil prices reported on IMF (2000, p. 277) to a 1998 oil price of $\$ 12.30$ a barrel. For the interest rate, we combine the projections for the real world long-term interest rate (IMF, 2000, p. 277) with the projections for U.S. CPI inflation (IMF, 2000, p. 215). For the world growth rate, we use the projections reported on IMF (2000, p. 277). 
Figure 5. 95 percent Confidence Band for Forecasts of Global Discrepancy (percent of World Imports)

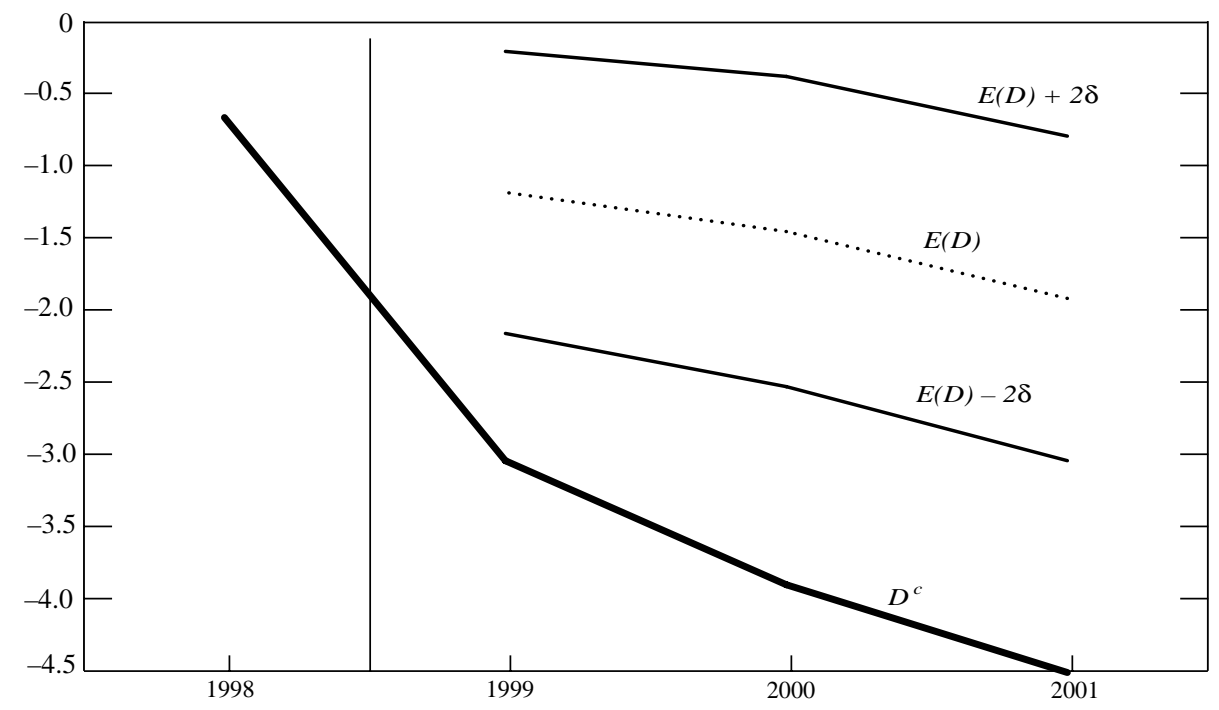

Table 7. Assumptions for Exogenous Variables

$\begin{array}{cccc} & P_{o} & & \\ \text { (in U.S. dollars } & R & d Y / Y \\ \text { per barrel) } & \text { (in percent) } & \text { (in percent) } \\ 1999 & 17.1 & 5.4 & 3.3 \\ 2000 & 23.1 & 6.2 & 4.2 \\ 2001 & 18.7 & 6.3 & 3.9\end{array}$

Source: IMF (2000).

\section{Conclusions}

This paper offers a framework for judging when the discrepancy embodied in current account forecasts is large. The first step in implementing this notion is to develop an econometric model that generates the discrepancy's conditional expectation. The second step is to compare this model-based forecast with the discrepancy embodied in countries' current account forecasts. If the gap in discrepancies is below a critical value, then the discrepancy embodied in the countries' current account forecasts is not large. Otherwise, the discrepancy is large and calls for a careful reexamination of the associated current account forecasts.

Econometric modeling of these discrepancies is not the obvious first step in addressing global discrepancies. The first obvious step is to design fixed rules to allocate the discrepancies across countries. Though appealing, reliance on rules is 
at odds with the large and often mutually offsetting movements in the discrepancies of the components of the current account and thus might further distort countries' current account forecasts. Econometric modeling of discrepancies, unusual as it is, offers a well-defined framework for determining when discrepancies in the global current account are unusual.

\section{APPENDIX}

\section{Data}

\section{Sources}

The published data on discrepancies come from various issues of the IMF's Balance of Payments Statistics. One needs to use several issues because the data are subject to large revisions. For example, the value for the 1994 discrepancy ranges from $-\$ 75$ billion in the 1995 data release to less than $-\$ 50$ billion in the 1998 data release. Thus each observation in Figure 1 comes from the most recent release containing data for that year. The exact dates of the releases can be found in the working paper version of this paper located at http://www.federalreserve.gov/pubs/ifdp/2000/678/ifdp678.pdf

The data for the other series also come from the IMF and the corresponding locators are given below:

Spot world U.S.\$ per barrel for oil: IMF 00176AAZ

Federal funds rate: IMF 11160B

World imports: IMF 00171D

U.S. imports: IMF 11171D

GDP growth: IMF 1997 Balance of Payments Yearbook, "GDP at Constant Prices," p. 144-45

\section{Properties}

The regressions presented earlier assume that the variables have the same degree of stationarity. To test whether that property holds, we use an Augmented Dickey-Fuller (ADF) test with a constant and three lags. The evidence suggests that one cannot reject the hypothesis that all of the variables used here are integrated of order one.

\section{Fixed Rules Allocation}

We now examine the issues involved in using fixed rules to allocate the "excess" or unexpected discrepancy among the countries and regions of interest. We start by considering hypothetical forecasts of global current accounts (Table A1), which embody a discrepancy of $-\$ 140$ billion. Suppose now that the model predicts a global discrepancy of $-\$ 40$ billion and the question is how to allocate the excess discrepancy ( $\$ 100$ billion) across the countries and regions in Table A1.

To this end, we assume that the global current account discrepancy stems from discrepancies in trade, shipping, and portfolio income; we ignore discrepancies in transfers. Then we allocate the discrepancy across countries using a list of stylized rules:

1. Take the forecast of the U.S. current account as given. 
Jaime Marquez and Lisa Workman

Augmented Dickey-Fuller Tests, 1972-98

$\begin{array}{lllr}\text { Exogenous Variables } & \text { ADF } & \text { Discrepancy } & \text { ADF } \\ \text { Price of oil } & -1.91 & \text { Trade } & -1.09 \\ \text { Federal funds rate } & -1.10 & \text { Income } & -1.88 \\ \text { U.S. share of world imports } & -2.05 & \text { Service } & -0.63 \\ \text { World growth } & -2.88 & \text { Transfers } & -2.02\end{array}$

Note: 5 percent value is -2.997 ; 1 percent value is -3.75 .

\begin{tabular}{|c|c|c|c|c|c|c|}
\hline \multicolumn{7}{|c|}{$\begin{array}{l}\text { Table A1. Hypothetical Allocation of the } \\
\text { Current Account Discrepancy for } 2001\end{array}$} \\
\hline & & \multicolumn{3}{|c|}{ Adjustments } & \multirow{2}{*}{$\begin{array}{c}\text { Total } \\
\text { Adjustment } \\
\text { (5) }\end{array}$} & \multirow[b]{2}{*}{$\begin{array}{c}\text { Final } \\
(6)\end{array}$} \\
\hline & $\begin{array}{l}\text { Original } \\
\text { (1) }\end{array}$ & $\begin{array}{l}\text { Trade } \\
(2)\end{array}$ & $\begin{array}{l}\text { Shipping } \\
\text { (3) }\end{array}$ & $\begin{array}{l}\text { Inc. } \\
(4)\end{array}$ & & \\
\hline United States & -422 & 0 & 0 & 0 & 0 & -422 \\
\hline Japan & 142 & 0 & 0 & +17 & +17 & 159 \\
\hline Euroland & 145 & -40 & 0 & +17 & -23 & 122 \\
\hline Other & 7 & 0 & +32 & +9 & +41 & 48 \\
\hline Asia & 59 & 0 & +18 & +12 & +30 & 89 \\
\hline Latin America & -56 & 0 & +10 & +9 & +19 & -37 \\
\hline Middle East and Africa & 1 & 0 & +6 & +4 & +10 & 11 \\
\hline Eastern Europe & -16 & 0 & +5 & 0 & +5 & -11 \\
\hline Discrepancy & -140 & -40 & +71 & +68 & +99 & -41 \\
\hline
\end{tabular}

2. Assume that the trade discrepancy is $+\$ 40$ billion (credits over debits). This estimate stems from the underreporting of imports in Euroland's business surveys (IMF, 1999, p. 4). Thus we lower the balance for Euroland by $\$ 40$ billion (Table A1, column 2).

3. Assume that the shipping discrepancy is $-\$ 71$ billion (debits over credits, 1997 value). Allocate this discrepancy to Eastern Europe ( 7 percent), Asia-as housing offshore banking centers-(25 percent), Middle East and Africa (8 percent), and other developing countries (60 percent). Assuming that "Other" includes Greece, we assign three-fourths of the 60 percent to Greece (IMF, 1987, Table 72).

4. Assume that the portfolio income discrepancy is $-\$ 68$ billion (debits over credits), which is half of the reported 1997 discrepancy; we use half of the income discrepancy to keep the overall discrepancy in the target range of $\$ 40$ billion. Allocate the $-\$ 68$ billion discrepancy as follows: 50 percent to industrial countries (25 percent for Japan and 25 percent for Euroland), 6 percent to Middle East and Africa, 18 percent to Asia, and 26 percent distributed evenly between "Other" and Latin America (IMF, 1987, Table 56).

Column 6 reports the final current account forecasts after the adjustments. The main change is the increase in the surplus of "Other" industrial countries due to the allocation of shipping exports to Greece. Otherwise, the allocation leaves intact the surplus/deficit status of each current account forecast. 


\section{MODEUNG THE IMF'S STATISTICAL DISCREPANCY}

Table A1 shows that allocating the excess discrepancy across countries with fixed rules is feasible but their use suffers from three limitations: ambiguities, disincentives, and lack of generality.

1. Ambiguities: There are many strategies to allocate the excess discrepancy, but there is no generally accepted method to discriminate among them. This ambiguity is not the result of using the model to estimate the expected discrepancy but rather stems from the abundance of degrees of freedom available in an exercise that allocates a whole to many parts.

2. Disincentives: If economists' forecasts of current accounts are bypassed by a fixed rule, then these economists could lose interest in forecast accuracy as their predictions can be overruled by the rule. Even if these economists do not lose their incentives, they will face a harder than needed task in trying to account for (and reduce) that forecast error. Indeed, fixed rules do not revise the paths for the forcing variables but rather the forecasts themselves, making detection of the source of the forecast error all that much harder.

3. Lack of generality: Organizational differences across institutions give rise to different allocation rules to accommodate institutional idiosyncrasies. What is suited to the IMF's purposes need not be suitable for the Organization for Economic Cooperation and Development or the World Bank.

These limitations are not meant to suggest that reallocation is not needed but, rather, to suggest that using a fixed rule is fraught with pitfalls that do not necessarily enhance forecast accuracy. There is a need to reallocate an excess discrepancy, but this process needs to be tailored to the particulars of the institution such as forecast assumptions, regional aggregates, and other features that might be pertinent. Our paper is not a contribution on how to allocate a discrepancy but rather on how much needs to be reallocated and, in this task, we hope the results of the paper are of general interest.

\section{REFERENCES}

Hendry, David F., and Jurgen Doornik, 1996, PcGive 9.0 (London: International Thomson Business Press).

Hollinger, Peter, and Leonid Spivakovsky, 1996, Portable Troll (Needham, Massachusetts: Intex Solutions).

IMF, 1987, Report on the World Current Account Discrepancy (Washington: International Monetary Fund).

— 1996, World Economic Outlook, October (Washington: International Monetary Fund). , 1997, Balance of Payments Statistics Newsletter, Volume V (June) (Washington: International Monetary Fund).

— , 1999a, IMF Committee on Balance of Payments Statistics: Annual Report 1998 (Washington: International Monetary Fund).

— 1999b, World Economic Outlook, October (Washington: International Monetary Fund).

— , 2000, World Economic Outlook, May (Washington: International Monetary Fund).

Sheets, Nathan, 1998, "Modeling the Global Discrepancy" (unpublished; Washington: Federal Reserve Board). 